\title{
Silicon Valley as an Early Adopter for On-Demand Civil VTOL Operations
}

\author{
Kevin R. Antcliff*, Mark D. Moore ${ }^{\dagger}$, and Kenneth H. Goodrich* \\ NASA Langley Research Center, Hampton, VA, 23681
}

\begin{abstract}
With high incomes, long commutes, severe ground geographic constraints, severe highway congestion during peak commute times, high housing costs, and near perfect year-round weather, the Silicon Valley is positioned to be an excellent early adopter market for emerging aviation On-Demand Mobility transportation solutions. Prior efforts have attempted to use existing aviation platforms (helicopters or General Aviation aircraft) with existing infrastructure solutions, or only investigated new vehicle platforms without understanding how to incorporate new vehicle types into existing built-up communities. Research has been performed with the objective of minimizing door-to-door time for "Hyper Commuters" (frequent, long-distance commuters) in the Silicon Valley through the development of new helipad infrastructure for ultra-low noise Vertical Takeoff and Landing (VTOL) aircraft. Current travel times for chosen city-pairs across urban and suburban commutes are compared to future mobility concepts that provide significantly higher utilization and productivity to yield competitive operating costs compared to existing transportation choices. Helipads are introduced near current modes of transportation and infrastructure for ease-ofaccess, and maximizing proximity. Strategies for both private and public infrastructure development are presented that require no new land purchase while minimizing community noise exposure. New VTOL concepts are introduced with cruise speeds of $200 \mathrm{mph}$, which yield a greater than three times improvement in overall door-to-door time when compared to current automobiles, and in some cases, improvements of up to 6 times lower trip times.
\end{abstract}

\section{Introduction}

$\mathrm{T}$ HE aerospace industry has entered an exciting period of start-up companies that are pushing aggressive technologies to enable new aviation markets. Likely such a fertile swelling of bold ideas backed with serious venture capital hasn't been seen by the aviation industry for 50 years. One such example includes Google and Facebook establishing companies to pursue Atmospheric Satellite aircraft that can provide omnipresent, inexpensive broadband wireless communication platforms with far lower latency than distant space-based satellites. ${ }^{1}$ Another is Makani (now acquired by Google) and a host of small companies with support from universities pursuing Airborne Wind Energy. ${ }^{2}$ This new market is seeking to use tethered Unmanned Aerial Systems (UAS) to enable extraction of far greater energy with greater consistency than ground-based wind turbines due to these aircraft operating at altitudes up to 2,000 feet, well above the Earth's boundary layer yet within the limits of FAA ground obstacles. Civil package delivery small UAS are being developed by a plethora of small companies along with giants including Google, Amazon, DHL, and Alibaba., ${ }^{3,4,5,6}$ These companies pursue developing Vertical Takeoff and Landing (VTOL) aircraft at gross weights below $55 \mathrm{lbm}$ that will be capable of immediate delivery of lightweight $(<5 \mathrm{lbm})$ merchandise through highly distributed operations at low altitudes ( $<500$ feet). All of these emerging aviation missions and business cases share a common characteristic, that is, they support a macro industry trend to provide increased on-demand capabilities, i.e. the ability to provide services whenever and wherever customers desire services. Aviation has a unique ability to meet future on-demand services, as it is essentially unencumbered by ground-based limitations, along with the ability to achieve greater distribution and speed. Combined, these capabilities yield the potential for vehicles with far greater 'reach', which can effectively amortize higher operating costs through high productivity. This paper focuses on a first principles investigation of another emerging aviation market, which shares these same characteristics, offering the potential for transformational On-Demand Mobility (ODM) through intra-urban aerial

\footnotetext{
* Aerospace Engineer, Aeronautics Systems Analysis Branch, MS 442, Member AIAA.

${ }^{\dagger}$ Aerospace Engineer, Aeronautics Systems Analysis Branch, MS 442, Senior Member AIAA.

* Aerospace Engineer, Dynamic Systems and Control Branch, MS 308, Senior Member AIAA.
} 
personal transportation. Small companies such as Zee.Aero, Joby Aviation, eVolo, Diamond, eHang, Terrafugia, and Lilium are developing electric propulsion and autonomy vehicle technologies packaged together in unconventional, non-rotorcraft-based VTOL concepts. ${ }^{7}$ The question being asked by these small companies is whether new choices can be provided that rise above the highly congested one-dimensional ground highway ant-trails to take advantage of three dimensions and create pathway-independent transportation solutions.

A meaningful investigation of urban Air-Taxi's involves operations which are inherently performed in close proximity to highly built-up geographic areas. Such aviation trips will invoke a large number of highly specific constraints, which are tightly coupled to the overall Concept of Operations (CONOPs). Instead of assuming generic operations, the authors felt that the constraints would become most apparent by investigating specific geographic areas; and that this would in turn promote a more clear case for feasibility. While this paper is only reporting out on the first phase of this study, the intent is to map out a market feasibility path for each of the multi-disciplinary studies that need to be conducted. Aircraft design studies (and experimental validation) must establish VTOL concepts showcasing a radical reduction in community noise (likely needing to achieve a $20+\mathrm{dB}$ reduction), with improved safety ( $\sim 6 \mathrm{x}$ greater from a per mile traveled to equate with automobile safety), while being able to compete economically with ground-based transportation $(<\$ 1.50$ per mile to compete with Uber) with any surcharge relating to the timesaving benefit that can be achieved. Demand modeling studies need to establish current intra-urban transportation trends, which in turn help to lock down the vehicle requirements (range, payload, speed) as well as the competitive transportation choices that are present (and the cost of each). Demand studies help to point to the most promising business models (market value price, fleet size, service area, vehicle utilization) as the value proposition that's being offered becomes clear. CONOPs studies need to be performed to decompose the trips into a set of operational requirements, which include ground distance portion, flight distance portion, wait/penalty times, takeoff and landing site limitations, altitude limitations, required supporting ground infrastructure, and level of distribution of ground infrastructure. Airspace studies provide the understanding of current airspace boundaries (class B hub airports) and how aircraft will be routed to avoid trajectory conflicts (which in turn provides an understanding of indirect routing penalties). A key question to be answered from the airspace studies is the overall capacity limitations of a geographic region (i.e. what is the maximum throughput or market potential given different spacing and control assumptions). Clearly, proving market feasibility will require layers upon layers of analysis results to be built-up over time, with iteration across each of these studies. Therefore the intent of this paper is not to provide a conclusive answer as to feasibility, but to start working these studies in combination to provide a foundation from which followup studies can be performed.

The authors would like to point out prior related research, which also investigated intra-urban aerial transportation within the context of the Silicon Valley. The 'Hopper' study was performed by Stanford University and NASA Ames. ${ }^{8}$ This study primarily investigated a scheduled 'bus-like' transportation solution using conventional helicopters at a 30-passenger size with an extremely limited distribution of operating nodes $(<14$ across the entire region). Investigation was focused on the airspace capacity given existing controller limitations, with an approach that extrapolates from current hub and spoke aviation to provide a hub and spoke intra-urban transportation solution. The Hopper study didn't look at true Door-to-Door (DtD) travel time savings as the evaluation metric. The current paper is considering a quite different approach, which pursues true on-demand transportation capability (i.e. 'car-like' trips) with a dramatically higher level of distribution. Two important factors relate to the selection of this new direction of research. As will be discussed, one of the most significant factors in achieving a high value of DtD time savings is the ground proximity distance to where users are attempting to travel (due to ground travel speeds during peak hours that are 10x slower than air travel speeds). Therefore, unless ground distances can be minimized, the benefit case is greatly diminished. Another key factor in maximizing the DtD speed is to minimize the infrastructure wait/penalty times associated with accessing the air vehicle (enplaning/deplaning, security, delays, etc.). The more centralized the solution, the greater the overhead wait/penalty times (i.e. accessing a bus station with only a few central stops versus getting in your car almost anywhere). A final major difference with the research in this paper is the level of criticality that community noise factors into the feasibility of these operations in urban areas. No matter what the technology utilized to achieve VTOL capability, the community noise scales proportionally with the vehicle gross weight. Lower tip speed propellers or rotors may be used, independent of the aircraft size, however, a larger aircraft will be louder. In the case of a 30 passenger VTOL versus a 4 passenger VTOL, with a proportional scaling such a vehicle would be 7 times louder. It is the belief of the authors that no other factor defines the feasibility of this market more than the ability to achieve the absolute quietest operations possible. San Francisco validates this belief, with essentially all helicopter operations prohibited because of noise (only one hospital helipad exists in the entire city and 
even that has severe local noise restrictions enacted). Therefore, the authors are attempting to maximize the DtD trip speeds while minimizing the community noise experienced by this new aviation mission.

\section{Background}

The greater San Francisco-Silicon Valley area has several characteristics that make it interesting from the perspective of evaluating the impact of alternative means of daily travel, particularly commuting between home and work. For the purposes of this paper, the area of interest is the San Jose-San Francisco-Oakland combined statistical area in California. For brevity, this combined area is often referred to as the Silicon Valley (due to the high concentration of companies involved in the invention of silicon semiconductors). The Silicon Valley area ranks as the fifth most populous metropolitan region in the United States (U.S.) and second in California. Due in part to notoriously expensive housing prices, the area has a high percentage of long-distance commuters. ${ }^{9}$ Table 1 shows that of the U.S. metropolitan areas with the highest mean distance for full-time working commuters, the three areas with the highest concentration of "mega commuters" are located in the Silicon Valley area. ${ }^{10}$

Table 1. Areas with the highest mega commuting distances

\begin{tabular}{|l|c|}
\hline \multicolumn{1}{|c|}{ Metro Areas with Highest Mean Distance } & $\begin{array}{c}\text { Percent Mega } \\
\text { Commutes }\end{array}$ \\
\hline San Francisco-Oakland-Fremont, CA & 2.06 \\
\hline San Jose-Sunnyvale-Santa Clara, CA & 1.90 \\
\hline Salinas, CA & 1.23 \\
\hline Gulfport-Biloxi, MS & 0.94 \\
\hline Hinesville-Fort Stewart, GA & 0.93 \\
\hline Lawton, OK & 0.82 \\
\hline Fayetteville, NC & 0.73 \\
\hline Brunswick, GA & 0.64 \\
\hline Anchorage, AK & 0.25 \\
\hline Honolulu, HI & 0.08 \\
\hline
\end{tabular}

The term mega-commuter refers to commuters who have a one-way travel distance or time to work greater than either 90 minutes or 50 miles. In addition to these mega commuters, according to Schafer, approximately $25 \%$ of the population can be expected to have total average travel times of 90 minutes or longer each day as shown in Figure $1 .{ }^{11}$

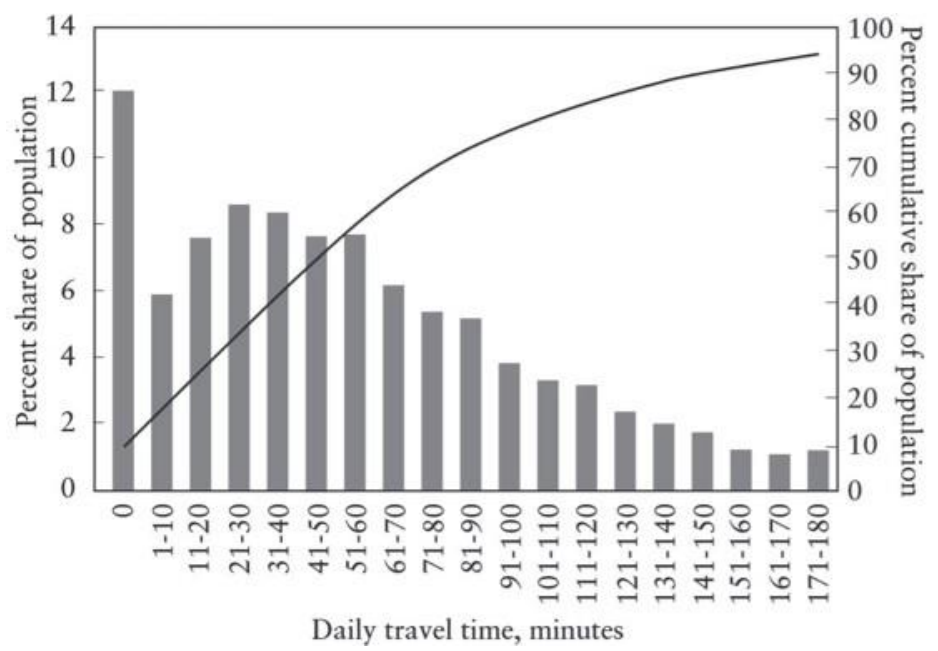

Figure 1. Daily personal travel distance distribution for the US

To assess what these trips might look like at "street level", two sets of representative city-pairs were selected to reflect both shorter-distance "urban" commutes and longer-distance "suburban" commutes. The selected city pairs are shown in Table 2 and Table 3, respectively for the urban and suburban pairings. 
Table 2. Representative urban city-pairs in the Silicon Valley

\begin{tabular}{|c|c|c|c|c|c|c|}
\hline \multirow[b]{2}{*}{ City 1} & \multirow[b]{2}{*}{ City 2} & \multicolumn{2}{|c|}{$\begin{array}{c}\text { Ground } \\
\text { Travel Time } \\
\text { (min) }\end{array}$} & \multirow[t]{2}{*}{$\begin{array}{l}\text { Driving } \\
\text { Distance } \\
\text { (miles) }\end{array}$} & \multicolumn{2}{|c|}{$\begin{array}{l}\text { Average } \\
\text { Speed } \\
\text { (mph) }\end{array}$} \\
\hline & & $\begin{array}{l}\text { Non- } \\
\text { Peak }\end{array}$ & Peak & & $\begin{array}{l}\text { Non- } \\
\text { Peak }\end{array}$ & Peak \\
\hline H.M. Bay & San Fran. & 40 & 75 & 30 & 45 & 24 \\
\hline Santa Cruz & Mt. View & 45 & 110 & 36 & 48 & 20 \\
\hline Morgan Hill & Palo Alto & 45 & 120 & 38 & 51 & 19 \\
\hline San Fran. & San Jose & 55 & 90 & 48 & 53 & 32 \\
\hline Fremont & Cupertino & 30 & 75 & 25 & 50 & 20 \\
\hline Pleasanton & Sunnyvale & 40 & 100 & 28 & 43 & 17 \\
\hline Walnut Crk. & Daly City & 40 & 110 & 32 & 49 & 18 \\
\hline Oakland & Stanford & 55 & 120 & 36 & 39 & 18 \\
\hline San Rafael & Fremont & 55 & 110 & 49 & 53 & 27 \\
\hline \multirow[t]{2}{*}{ Mill Valley } & RW City & 60 & 120 & 40 & 40 & 20 \\
\hline & Average: & 47 & 103 & 36 & 47 & 21 \\
\hline
\end{tabular}

The geocoded reference points for a city were used to represent the origin and destination of trips to and from that city. Google maps were then used to evaluate the best street routes and associated driving distance, travel times, and speeds as included in Table 2 and Table 3. The tables include expected peak and non-peak travel time estimates that reflect both the expected trip time in ideal traffic conditions (non-peak) and typical rush-hour conditions (peak). Average speeds were calculated as travel distance divided by time and do not reflect actual expected vehicle speeds at any point during a trip.

Table 3. Representative suburban city-pairs in the Silicon Valley

\begin{tabular}{|c|c|c|c|c|c|c|}
\hline \multirow[b]{2}{*}{ City 1} & \multirow[b]{2}{*}{ City 2} & \multicolumn{2}{|c|}{$\begin{array}{c}\text { Ground } \\
\text { Travel Time } \\
\text { (min) }\end{array}$} & \multirow[t]{2}{*}{$\begin{array}{l}\text { Driving } \\
\text { Distance } \\
\text { (Miles) }\end{array}$} & \multicolumn{2}{|c|}{$\begin{array}{l}\text { Average } \\
\text { Speed } \\
\text { (mph) }\end{array}$} \\
\hline & & $\begin{array}{l}\text { Non- } \\
\text { Peak }\end{array}$ & Peak & & $\begin{array}{l}\text { Non- } \\
\text { Peak }\end{array}$ & Peak \\
\hline Monterey & San Fran. & 120 & 220 & 119 & 60 & 33 \\
\hline Los Banos & Mt. View & 90 & 180 & 91 & 61 & 30 \\
\hline Stockton & San Jose & 90 & 150 & 76 & 50 & 30 \\
\hline Modesto & Palo Alto & 90 & 210 & 89 & 59 & 25 \\
\hline Sacramento & San Fran. & 90 & 200 & 88 & 59 & 26 \\
\hline Napa & Mt. View & 90 & 200 & 86 & 57 & 26 \\
\hline Santa Rosa & Cupertino & 110 & 200 & 107 & 58 & 32 \\
\hline Merced & Mt. View & 130 & 200 & 127 & 59 & 38 \\
\hline Merced & San Mateo & 130 & 200 & 128 & 59 & 38 \\
\hline Los Banos & Fremont & 90 & 150 & 95 & 63 & 38 \\
\hline Sacramento & Oakland & 80 & 160 & 82 & 61 & 31 \\
\hline S.Lake Tahoe & Palo Alto & 220 & 340 & 219 & 60 & 39 \\
\hline \multirow[t]{2}{*}{ Redding } & San Fran. & 190 & 310 & 217 & 68 & 42 \\
\hline & Average: & 117 & 209 & 117 & 60 & 34 \\
\hline
\end{tabular}

An example urban route between Oakland and Stanford is shown in Figure 2. It is interesting to note that the distance by road is 1.34 times longer than the great-circle distance. A representative suburban trip between Modesto and Palo Alto is shown in Figure 2 as well. In this case, the distance by road is 1.38 times longer than the direct distance. When VTOL flight vehicles capable of operating from heliports located in close proximity to the city reference points are considered in a later section, their ability to approximately fly these direct routes results in travel 
distance reductions averaging 20\% for the urban trips and 30\% for the suburban as compared to the corresponding onroad distances.



(a)

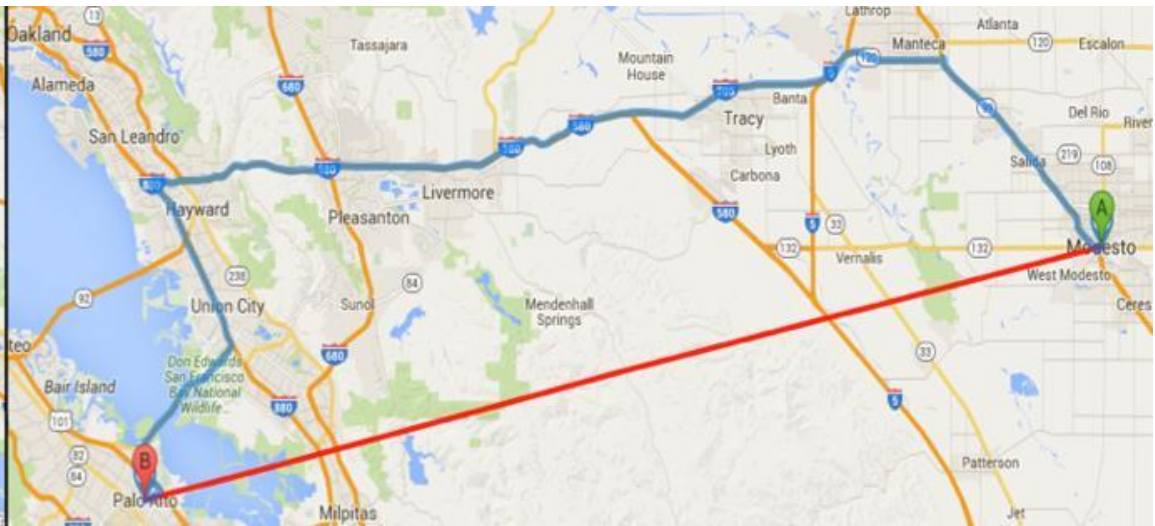

(b)

Figure 2. An example urban route (a) and an example suburban route (b). The red lines represent great circle distance, while blue lines represent shortest car travel distance.

Setting the stage for the upcoming comparisons between these car-based commuter trips and aerial commuting, it is important to consider the location of available air-ground infrastructure (i.e. runways and helipads) as needed by a given class of vehicle. For airplanes with conventional takeoff and landing (CTOL) requirements, this is relatively straightforward as these vehicles really can only operate from existing airports. For these vehicles, trips had two ground segments, one from the origin city to the nearest airport and the second from the airport nearest the destination to destination. As will be explained later, a standard flight profile was used between the two airports. As will also be explained in the following section, for vehicles needing ground infrastructure shorter than conventional runways, studies were conducted to assess the potential to widely distribute the needed infrastructure around the Silicon Valley area in an effort to reduce ground segment distances. It should be recognized that in addition to shortening the needed ground segments, this highly distributed air portal infrastructure has the advantage of creating a node-based transportation system in which the loss of individual nodes will have a limited impact on the system's throughput and individual trip times. In contrast, trips made entirely by road usually only have one or two practical routes and are thus vulnerable to disruptions and high travel uncertainty by factors like an accident effectively closing down a selected route.

\section{Infrastructure Siting Requirements}

New types of flight vehicles capable of operating from air-ground infrastructure smaller than conventional runways have the potential to increase door-to-door trip speeds by reducing ground segment times. Of course, even though such infrastructure might require less space than a conventional runway, the ability to integrate it into already developed areas is a major challenge. In this section, the space requirements and other constraints for advanced, short, extremely short, and vertical takeoff and landing operations were estimated (e.g. STOL, ESTOL \& VTOL) before considering potential siting locations within the Silicon Valley area.

To estimate first-order siting requirements, protected ground and approach and departure surface recommendations from the FAA and the more subjective issue of overflying adjacent private property at low altitude during takeoff and landing operations were considered. Based on prior precedents (e.g. United States v. Causby), the assumption was made that at less than 500' above the ground overflights of property, not under the ownership or control of the facility operator, could not occur under normal operations. ${ }^{12}$ As shown in Figure 3, this overflight requirement results in property control requirements that severely limit the potential locations of STOL or ESTOL operations in existing densely developed areas. Others have promoted the idea of 'Pocket Airports' in urban areas, where short field lengths and high climb and approach angles could be used to minimize the required land space. This idea is conceptualized in Figure 3, with examples showing a 1000' field length and 12 degree glideslope, as well as 500' with 20 degrees, $250^{\prime}$ with 30 degrees, and 100' with 45 degrees. As a guideline for how aggressive each of these field lengths and glideslopes can be, even extremely sporty/high risk bush/missionary STOL operations won't go beyond 500' field lengths and 20 degree glideslopes. But clearly from Figure 3, the amount of land required to accommodate any of these Pocket Airports would be highly expensive, and positioning them without incurring harsh complaints from 
neighboring property owners would be difficult, if not impossible, to get past local ordinances. Clearly the goal of these operations will be to minimize land required and surrounding private property land impacted by operations. Attempts were also made to position these different field lengths along highways, however insufficient land was present along most highway locations. In addition, prevailing wind direction limits the effectiveness of such airfields since takeoff and landings with 45 to 90 degrees to the wind will cause significant operational restrictions on availability. Based on this observation, the analysis was limited to only considering VTOL operations since these have the option of ascending and descending below 500' nearly vertically over a helipad property with independence from wind directionality. Locating any helipads must consider the ability for neighboring property to tolerate flight path operations and some reasonable level of noise. For this reason, being able to locate helipads adjacent to major public roadways provides an opportunity for approach and departure overflight to take place over these roadways, and in a location where relatively high levels of transportation noise already exists. Figure 3 also shows a proposed solution for accommodating helipads to meet all of these requirements, by utilizing existing Department of Transportation (DOT) land available in the major road artery cloverleafs. This proposed use will be explained in detail in Section IV of this paper.

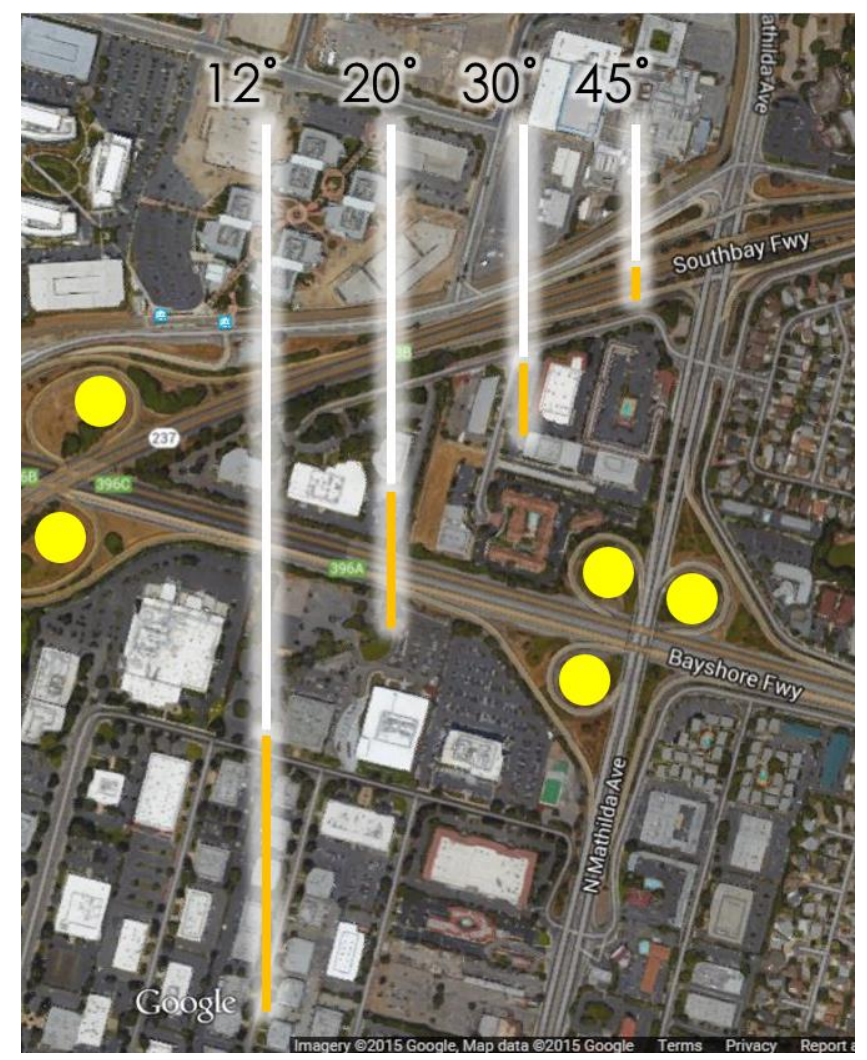

Figure 3. Potential runway field lengths and their required departure and approach path lengths at various climb or approach angles to meet a 500' minimum overflight altitude, versus cloverleaf helipads.

As a next step in assessing siting constraints for VTOL operations, the recommendations of the FAA for small helipads were adopted. ${ }^{13}$ These recommendations suggest a controlled ground area consisting of three concentric zones or areas: 1) a touchdown and liftoff (TLOF) area, 2) a final approach and takeoff (FATO) area, and 3) a safety area (SA). For this study, circular areas were used with diameters of 50', 100', and 200' respectively for the TOLF, FATO, and SA. In addition to these areas on the ground the FAA recommends two approach and departure paths with underlying obstacle protection surfaces sloping up from the FATO with an 8:1 primary gradient as shown in Figure 4. These are the basic helipad siting constraints used in the reminder of the study. It should be recognized that the ground and air protected areas are based on recommendations for visual operations and that the current protection requirements for instrument operations in low-visibility conditions (i.e. instrument meteorological conditions) are much larger. It is expected that these VTOL aircraft would also include advanced navigation and avionics capabilities 
supporting safe operations, independent of visibility, within today's visual operating envelope. Likely the navigation and avionics piloting aids would involve a combination of centralized, vehicle to vehicle, and localized helipad information sharing. Achieving the minimal amount of localized helipad support (i.e. broadcasting of takeoff and approach order and sequencing) is desired to keep the cost of each helipad low so that the maximum level of helipad distribution can be achieved (and therefore maximize the trip speed while minimizing the ground travel required to complete the door to door trip).

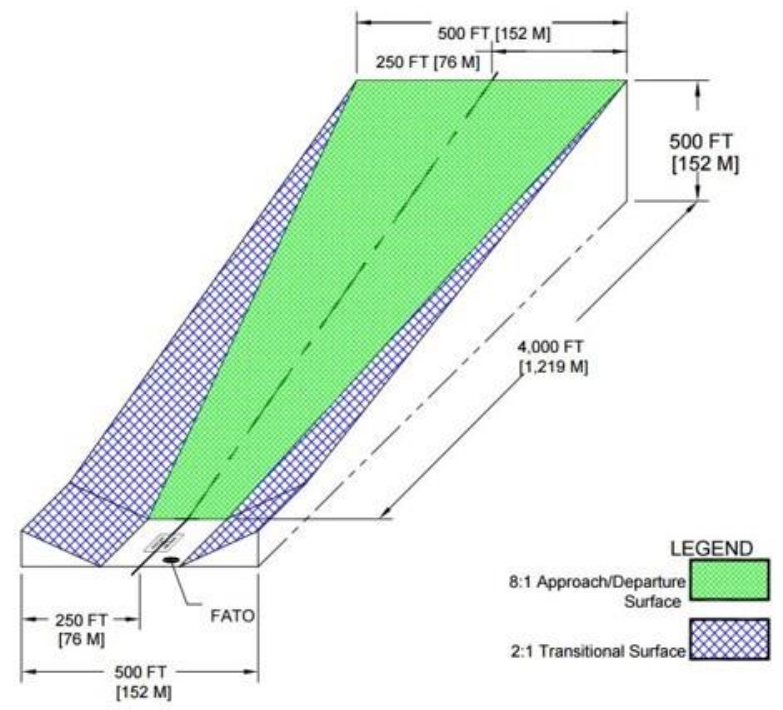

Figure 4. Recommended approach and departure protection surfaces adjoining final approach and takeoff area

\section{Infrastructure Development}

Using these requirements as a guide, helipad sites were selected in various locations across the Silicon Valley area. These locations include both public infrastructure, for both urban and metropolitan settings, as well as private infrastructure to provide transportation access to the numerous technological companies in the area.

\section{A. Public Infrastructure (Urban)}

The requirements for the placement of uniformly distributed helipads within the current congested urban environment are challenging to fulfill. However, in all urban areas well-designed and evenly distributed transportation hubs have already been established through the use of cloverleaf interchanges. These interchanges are ideal for the implementation of this concept for various reasons:

1. The land is owned by either state or federal government and allows for approach and departure paths without overflight of private property at an altitude of less than 500'

2. Roadways are an existing high noise area that the community accepts with established setbacks and/or noise barriers.

3. Cloverleaf interchanges are highly distributed and are coupled with existing ground thoroughfares to minimize travel time.

Figure 5 shows two schematics displaying the proposed integration of helipads into a cloverleaf interchange. The first schematic exhibits the 200' safety area fully contained within the limits of all four cloverleafs, while also showing the typical 200' setback distance adjacent to private land. Based on a 30 degree glide slope and this setback distance, the aircraft must ascend/descend vertically for $385^{\prime}$ before initiating forward flight. The second presents the roadway change to allow for an airport-like pick-up and drop-off zones for shared services such as Uber, Lyft, or local taxi companies. However, in an effort to not limit the potential vehicle concepts, this schematic also includes the potential for roadable aircraft with a driveway-like on/off-ramp. In this schematic, you will also notice that the public safety area would be clear of any obstructions, but not paved, which is typical of most current urban helipads. 


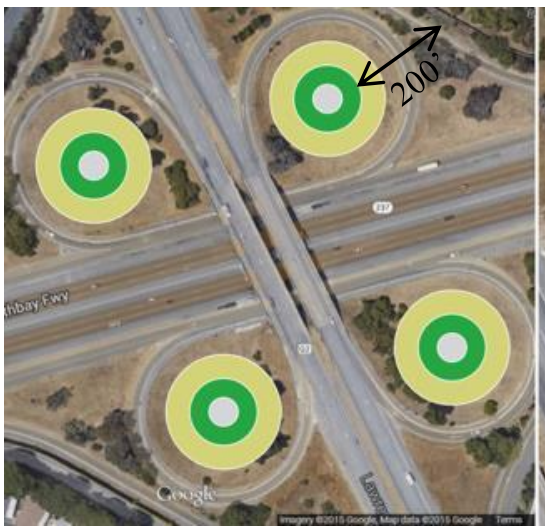

(a)

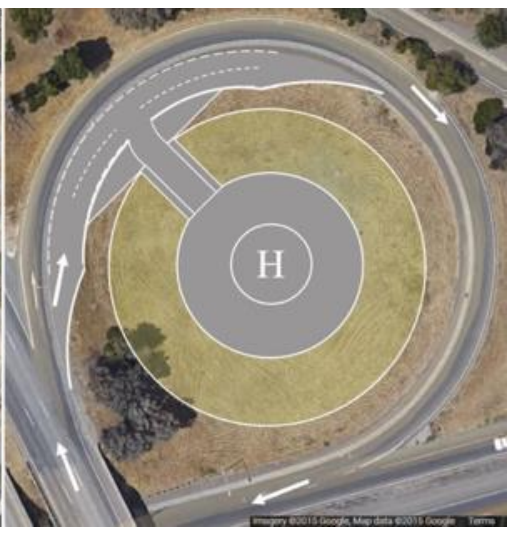

(b)

Figure 5. Public urban helipad placement. Full cloverleaf-helipad integration (a) and single cloverleaf-helipad displaying connection with current road (b).

To fully explore this proposed new infrastructure and CONOPs within the Silicon Valley area, a distribution of helipads must be determined. For this study, a 10 square mile area at the boundary of Mountain View and Sunnyvale was chosen as a representative region. All cloverleafs at each interchange were inspected to determine if there was a) available land with a diameter greater than 200' and b) an absence of flight or ground obstructions. As an example, the center intersection indicated by a red arrow in Figure 6 was an excellent candidate for this new infrastructure, but was not included because of its proximity to an active runway at Moffett Federal Airfield. Out of the 10 cloverleaf interchanges, 19 potential helipad sites were selected.

Based on this discovery, a value of 1.9 helipads per cloverleaf interchange was calculated to estimate the potential helipad sites in the urban portion of the Silicon Valley. An aerial view of the Silicon Valley was then used to handpick each interchange with at least one cloverleaf, which resulted in 105 total urban intersections. This value multiplied by the 1.9 helipads per interchange resulted in 200 potential helipad sites over the 280 square miles of the urban portion of the Silicon Valley thus resulting in 0.71 potential helipad sites per square mile. This ground separation distance will be used in Section VI to determine the ground travel distance portion of door-to-door speed.

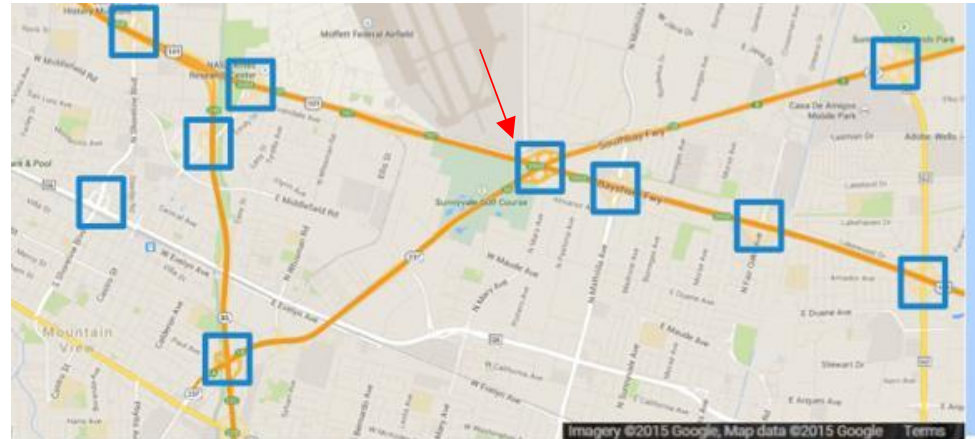

(a)

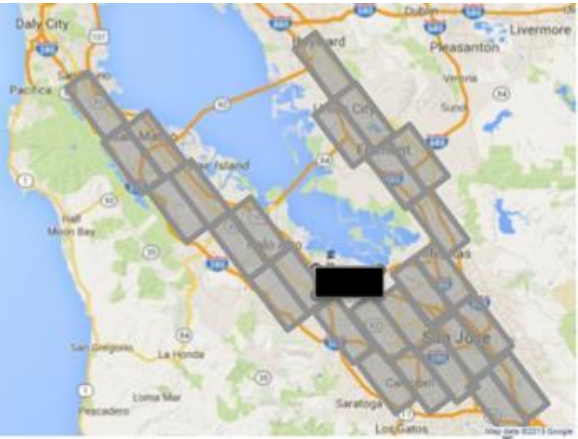

(b)

Figure 6. Public urban Silicon Valley placement. Cloverleaf interchanges within a 10 square mile region (a) and the total urban portion of the Silicon Valley investigated for this study $(b)$.

\section{B. Public Infrastructure (Metropolitan)}

The requirements for the placement of uniformly distributed helipads within a metropolitan area are even more difficult than for an urban landscape. Most metropolitan areas utilize diamond interchanges in lieu of cloverleaf interchanges due to minimal land availability. Therefore, a new solution must be determined for these areas. Fortuitously, many of the largest metropolitan areas were formed because of their proximity to a large body of water. 
Examples include large metropolitan areas such as: New York City, Los Angeles, Chicago, St. Louis, Minneapolis, and San Francisco. Therefore, low land availability and close water proximity lends to a helipad-barge solution, similar to those currently employed by companies like Helijet, as shown in Figure 7a.

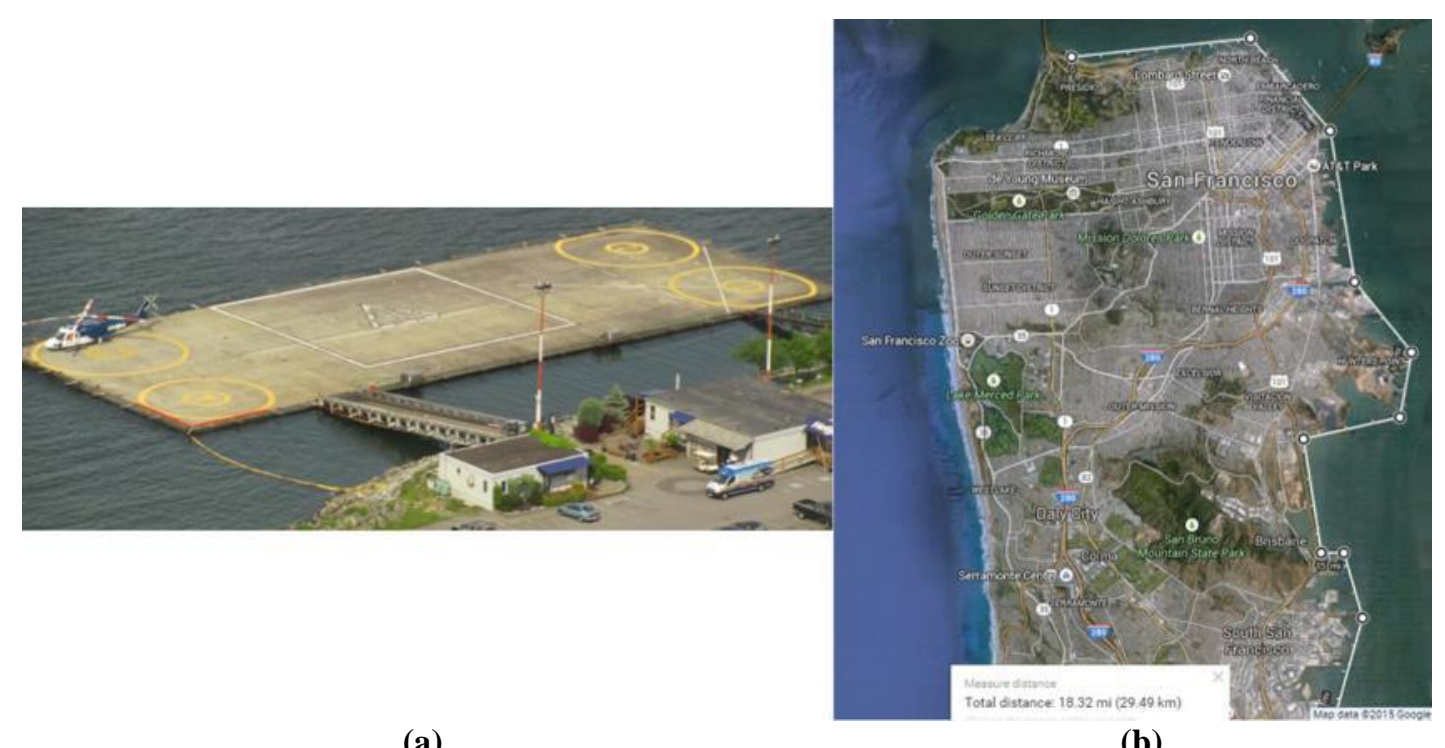

(a)

(b)

Figure 7. Public metropolitan helipad placement in the Silicon Valley. A barge used for helicopter operations (a) and the potential coastline available for heliport barge operations (b).

A map of the over 18 miles of San Francisco bayside coastline that was investigated is shown in Figure 7b. This side of the peninsula was chosen due to its close proximity to the population, low frequency of strong ocean waves, and direct access to roads that are in close proximity to the coastline. The FAA transitional surface guideline (shown in Figure 4) states that there should be no flight obstructions within 250' of the helipad in the direction perpendicular to the flight path. To be selected as a potential helipad site, a distance between helipads of 500' was necessary based on this requirement. Therefore with selection criteria of 500' spacing and direct road access, 50 helipads were handpicked along the San Francisco coastline. Then, with a land area of 47 square miles, 0.94 square miles per helipad was used for the metropolitan area.

\section{Private Infrastructure}

With the high numbers of tech companies in the Silicon Valley, there is potential for early adoption of this transportation solution in the private sector. Therefore, a square block containing tech companies (Google Tech Corners, Rambus, Microsoft, GoDaddy, and Motorola) was investigated to understand the potential of private helipad integration. Figure 8 displays the satellite view of the studied area.

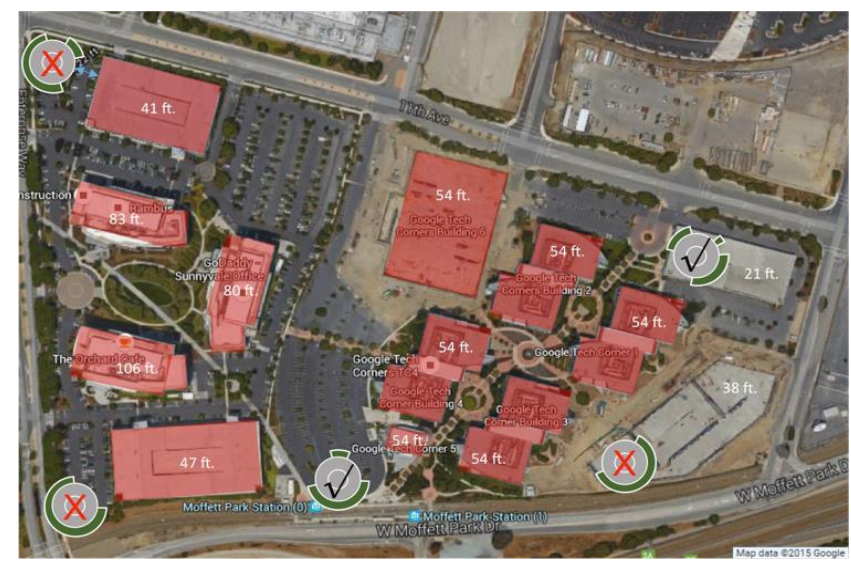

Figure 8. Private helipad Silicon Valley example 
It was assumed that all companies in this square block were involved in the development of this new transportation option, which allowed for flight over all land within this square block. As with the urban and metropolitan public helipads, a few constraints were imposed on the placement of the helipads, which included no flight over private land at 500', the ability to take off in any wind condition with a maximum of a 45-degree crosswind, and must meet the FAA helipad approach/departure path standards shown in Figure 4. As a reminder, these standards state that no obstructions should be within an 8:1 approach/departure surface in the direction of flight or within a 2:1 transitional surface perpendicular to the direction of flight.

Five potential helipad sites were placed. Then, each of these potential locations were inspected further to determine whether they met the constraints. The green areas surrounding the helipads (in Figure 8) represent the approach/departure paths that meet all of the constraints. Three of the five were not selected because a nearby building would intersect the 8:1 approach/departure surface, and create a greater than 90 degree azimuth angle, which would violate the 45-degree crosswind constraint.

Figure 9 gives a more detailed look at the possible approach/departure paths of the helipad shown in the upperright of Figure 8. A "street view" of this helipad location on top of a parking garage is shown. Two of the areas where the approach/departure path was deemed to not meet the constraints are explained. The first was a 100' tall building that would intersect the 8:1 approach/departure surface. The second was private land that was only 140' from the helipad. As calculated in the Public Infrastructure (Urban) section, the assumed 385' vertical ascent/descent and 30 degree forward-flight glide slope would encroach on the greater than 500' private flyover requirement. Between the two areas where the constraints are not met, there is a small sliver of approach/departure paths that allow this helipad to fulfill the 45-degree crosswind requirement (Figure 8).

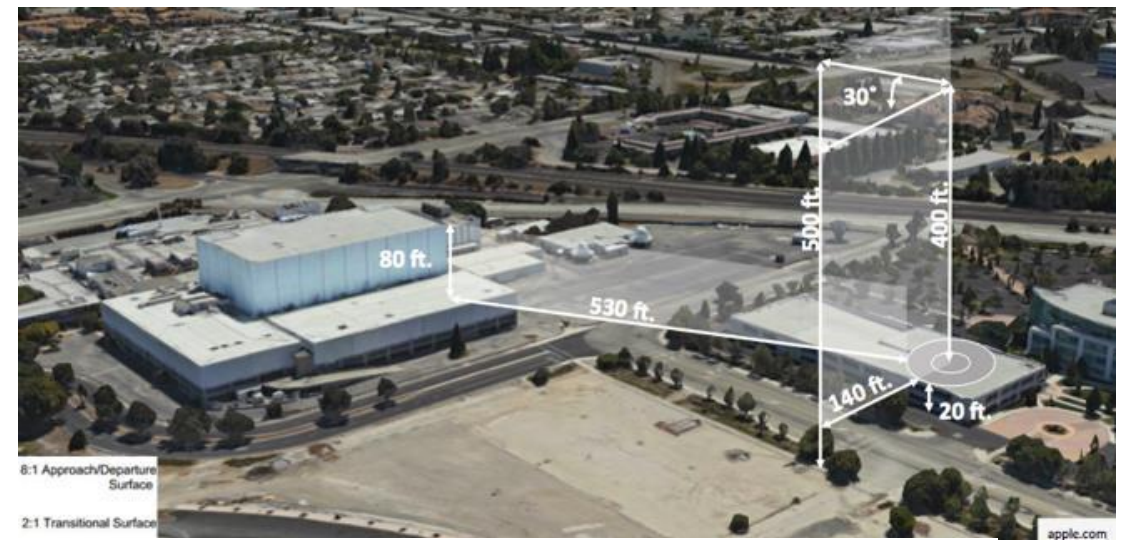

Figure 9. Private helipad approach/departure path example

While tech campuses may be early adopters of this new transportation system, there are many other potential opportunities for private and public helipads that were not mentioned or accounted for in this study. These include parking lots located at places of worship that are only used on Saturday or Sunday, large stadiums or concert venues that are left unused for large portions of the year, large superstores or malls, dedicated parking structures, large parks, and many more.

\section{Concept Requirements and Approaches}

With the potential to achieve a highly distributed infrastructure across urban areas at least theoretically established, the question becomes what sort of VTOL aircraft configuration can best accomplish the suggested missions. Any vehicle configuration design study begins with an understanding of the requirements imposed upon the vehicle. The prior analyses have established a basic understanding of the range ( 20 to 200 miles), and the required speed to achieve an effective DtD time savings benefit ( 120 to $200 \mathrm{mph})$. The most critical design constraint is not yet clearly understood, and that is the amount of acceptable noise that will be tolerated at these public and private helipads that are within several hundred feet of surrounding private property. In fact, more important than a specific $\mathrm{dB}$ noise level that would be tolerated across full day exposure to many flights, is developing an understanding of the level of annoyance developed from different noise signatures (and likely from VTOL aircraft that are quite different than existing helicopters). A rough rule of thumb that was agreed to across the authors was a similar level of noise as that experienced by trucks on roadways operating at 35 to $55 \mathrm{mph}$. Instead of specifying a setback distance, which will vary across helipad sites, a level of noise/annoyance at the border to any adjoining private property is assumed to be 
the active constraint. Based on a combination of prior truck-roadway noise studies, a level of $65 \mathrm{~dB}$ at the property line is considered the initial noise acceptability criteria. To put this level in context, a $2000 \mathrm{lbm}$ Schweizer 300C performing a 500' altitude flyover generates $~ 79 \mathrm{~dB}$, a $4000 \mathrm{lbm}$ Boeing MC600N (one of the quietest helicopters in the market) also generates $79 \mathrm{~dB}$, and a 12,000 lbm Sikorsky S-76C+ generates a $\sim 92 \mathrm{~dB} .{ }^{14}$ Proximity distances for public highway cloverleaf and private elevated parking structures are likely to accommodate a distance from VTOL aircraft to private property boundary of $\sim 250 \mathrm{ft}$, which equates to the prior helicopter noise levels increasing by $6 \mathrm{~dB}$ with a halving of the distance. Therefore, in the opinion of the authors, even light helicopters require a reduction in noise of $\sim 20 \mathrm{~dB}$ for a 3-6 person helicopter to meet frequent close proximity acceptability criteria (and $\sim 33 \mathrm{~dB}$ for a 10-12 person helicopter). A great deal more research is required to fully understand community noise acceptability for these type of operations, however a starting point was required to provide a basis since this constraint will be the most active in determining configuration feasibility. The helicopter noise examples provided show the trend of increased noise at larger passenger capacity and higher gross weight aircraft.

With range and speed requirements reasonably bounded, the next natural requirement question to raise is the payload/passenger size. Several factors influence this decision, but from the prior helicopter examples the greatest probability of meeting the severe noise constraints exists with smaller VTOL aircraft with fewer passengers. The ability of autonomy technologies also plays a major factor in the determination of this requirement, due to a 4 person aircraft currently having 1 pilot and 3 passengers. If autonomy can provide a mechanism to eliminate the pilot, the VTOL aircraft can become significantly lighter with a $25 \%$ reduction in payload capacity and weight (assuming autonomy requires minimal mass and volume). Autonomy becomes increasingly important as smaller (and quieter) VTOL aircraft are considered, with a single person solution being the ideal low noise vehicle, but unable to carry a passenger unless a self-flying capability is embraced. With smaller vehicles aligning with the noise constraint, the question becomes what passenger level is reasonable for on-demand air-taxi operations in urban areas. A reasonable reference to provide guidance on typical passenger trip size comes from the American Travel Survey, which tracks statistics relating to automobile transportation. ${ }^{15}$ This data shows that for trips less than 100 miles over $70 \%$ of all trips contain a single person and the average load factor is 1.3 people. For trips greater than 100 miles over $59 \%$ of all trips contain a single person and the average load factor is 1.6 people. Prior conventional takeoff air-taxis have remarkably similar statistics, with anecdotal evidence indicating load factors from companies such as DayJet and SATSAir having average passenger loads of 1.3 to 1.7. For these reasons, the payload for this study was assumed to be a 1 to 2 person capacity. This capacity permits true on-demand air-taxi operations with a near-term solution without autonomy still meeting $70 \%$ of trips for a single passenger, while the longer term autonomy enabled solution meeting $85+\%$ of trips with 2 passengers.

Additional discussion is necessary for the energy/fuel required beyond the required range. The term energy is used because most of the companies pursuing this mission are focused on electric propulsion solutions which both decrease the engine/motor noise and expands the opportunities to embrace new configuration types that can achieve lower propulsor noise than helicopter rotors. Energy required for this study was assumed to be not only sufficient for 200 miles range at best economy speed, but also energy to achieve 5 takeoffs and landings to support an average segment length of 40 miles, plus a 20 minute reserve loiter at best loiter speed. To account for battery depth of discharge, pure electric propulsion solutions were required to have $20 \%$ available in the batteries excluding the reserve loiter. Each takeoff and landing was assumed to require 60 seconds at full power to account for hover and transition to best climb speed.

Many other vehicle requirements and considerations should certainly be applied, but were beyond the scope of this study. Powered-lift fixed wing aircraft that are dependent on wing lift during hover/transition need to have some wind gust penalty applied to account for a worst case tailwind, likely something on the order of 10 knots and perhaps higher depending on geographic and local weather conditions. Control robustness and the ability to avoid the deadman's zone are important factors for these type of high frequency operations. These considerations suggest configurations that can achieve the fewest single fault designs (or even adopting concepts that are fully redundant in terms of hover lift generation) along with the fewest number of articulating components. High rates of descent are desirable to limit the amount of flyover land area under a 500' altitude. This will likely lead to the use of higher disc loading which helps to avoid entering the ring-vortex state that low disc loading helicopters experience in a rapid descent when the rotor induced velocity is lower than the rate of descent. One of the reasons higher disc loading can be embraced with this operational concept is that sustained hover for more than 30 to 60 seconds offer little value for this civil transportation-based mission. Also, many assume that disc loading is a primary factor in determining the amount of noise, which isn't accurate. Induced velocities resulting from higher disc loading are a minor noise contributor, while factors such as tip speed are a $5^{\text {th }}$ order determination. 

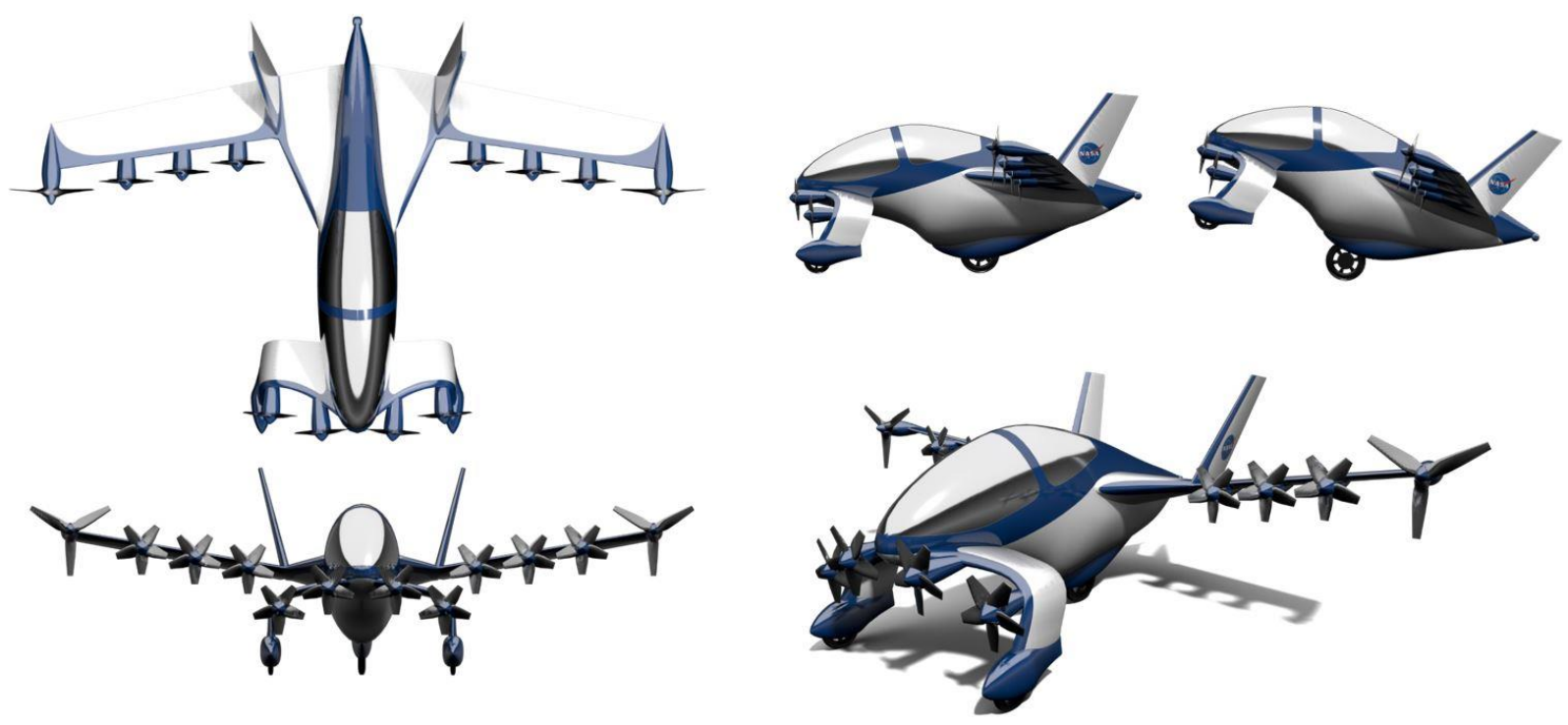

Figure 10. NASA Gridlock Commuter concept using Distributed Electric Propulsion.

While several specific concepts were generated as part of this study, they're not discussed in detail as part of this paper for several reasons. Foremost, this mission concept analysis is about far more than a singular vehicle approach and the authors wished for this content not to be judged by the strength or weakness of a single approach. In addition, the concept approaches generated are significantly different than existing helicopter products and require a full paper by themselves to provide a basis for defending the design. However, for completeness, one representative example is the Gridlock Commuter concept show in Error! Reference source not found. above. This concept was derived from a cross between the Ryan Vertiplane and the Vought V-173, shown in Error! Reference source not found. below. The intent of this concept was to highlight the new degrees of freedom made available from Distributed Electric Propulsion (DEP) technologies which provide a scale-free propulsion integration solution. Compact and highly reliable electric motors and propulsors are able to be integrated across the airframe without fuel consumption and specific power scaling penalties, enabling aircraft designers to achieve synergistic coupling between propulsion, control, lift generation, and drag reduction. This particular concept leverages 1.5' diameter folding propellers developed and tested as part of the NASA LEAPTech/HEIST research, as well as wingtip cruise propulsion. ${ }^{16}$ The inboard LEAPTech propellers (which were designed by Joby Aviation) are high solidity and low tip speed ( 450 $\mathrm{ft} / \mathrm{sec}$ ). This allows the propeller noise to be considerably quieter than existing propellers or rotors which are designed for 700 to $900 \mathrm{ft} / \mathrm{sec}$. The concept utilizes a powered-lift canard along with an extending main landing gear to achieve a vehicle rotation while on the ground and provide a 30 to 45 degree vehicle attitude prior to takeoff. No ground roll is required, but with the vehicle at a high angle of attack the canard and wing use full-span flaps to deflect the propeller flow and achieve a resultant vertical lift force (without forward motion due to the rearward facing canard and wing lift forces at the static condition). This concept approach leverages the ability to couple full-span DEP propulsor to achieve a fully-blown canard and wing with a significant portion of the hover lift provided by the lifting surfaces (as a result of the dynamic pressure the canard and wing experience). Such an approach highlights the potential for DEP to permit radically different VTOL aircraft concepts to be developed, without dependency on large rotors. While this concept requires far greater power in hover and transition than a helicopter, due to the mission, the total energy required for hover and transition is only a small portion of the total mission energy. Electric motors provide high power density (greater than $3 \mathrm{hp} / \mathrm{lbm}$ at continuous power rating and greater than $5 \mathrm{hp} / \mathrm{lbm}$ for short duration peak ratings). Therefore, the increased weight associated with the increased power required for takeoff and landing is not a significant penalty. The more important consideration for this mission is the aerodynamic and propulsive efficiency that can be achieved during the cruise, where most energy is consumed. This concept is capable of achieving a best efficiency Lift/Drag ratio at 120 knots of $\sim 14$, along with an installed cruise propulsive efficiency of $\sim 100 \%$ due to energy recovery from the wingtip vortex propellers. This compares to a typical helicopter aerodynamic efficiency of a Lift/Drag ratio less than 5, and a cruise propulsive efficiency of $\sim 80 \%$. Combining the aerodynamic and propulsive efficiencies, the specific range of the Gridlock Commuter is 3.5x greater than a typical helicopter. It's this exciting new ability to achieve cruise efficient VTOL aircraft that don't require hover efficiency which promotes the possibility of achieving economically viable air-taxi solutions. 


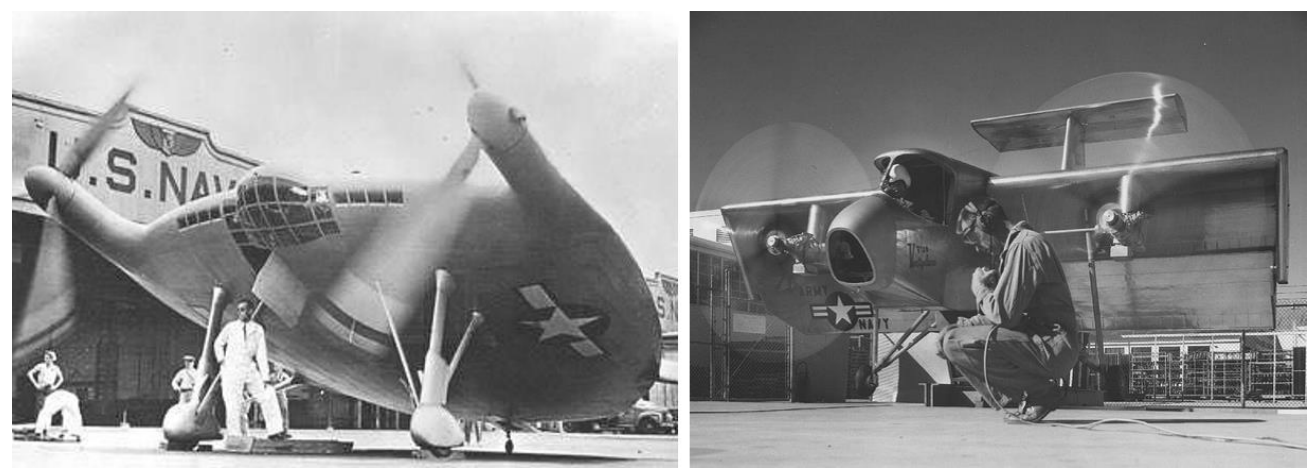

Figure 11. Vought V-173 and Ryan Vertiplane VSTOL concepts

\section{Results}

With a vehicle concept and distribution of helipad sites determined, a comparison can be made between this ondemand mobility (ODM) solution and current road travel in the Silicon Valley. The first step in quantifying the DtD time of this ODM solution was to convert the square miles per helipad values into an average block time estimate for ground travel. For the metropolitan and urban areas, values of 0.94 and 1.4 square miles per helipad, respectively were determined. If assuming even distribution of these helipads in metro and urban areas, the maximum commute to a helipad would be 0.66 and 0.99 miles, respectively. Therefore, based on peak travel speeds (as calculated in the Background section) the metropolitan and urban will have block ground travel times of 1.9 and 2.8 minutes, respectively. It was also conservatively assumed that suburban areas will have similar ground travel times to urban areas due to cheaper land acquisition cost, less constraining setback obstacles, and faster peak travel speeds.

Figure 12 describes the mission profile and average mission block time buildup. A cruise altitude of 2,500 and 5,500 ' were assumed for the urban (incl. metropolitan) and suburban flights, respectively. Vertical takeoff and landing speeds were assumed to reach 200' per min. and forward flight climb and descent rates were assumed to reach 1,000' per min. With these assumptions and average flight distances, average block time buildups were determined for all 4 possible routes using an assumed cruise speed of $120 \mathrm{mph}$.

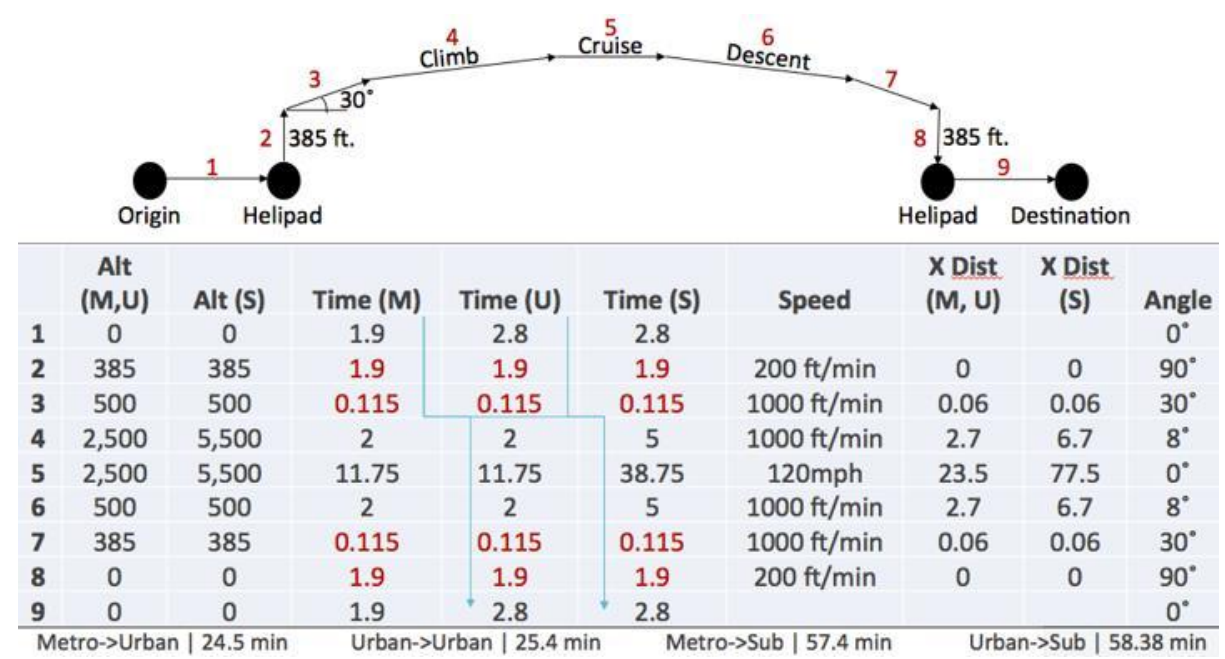

Figure 12. Average mission block time buildup with $120 \mathrm{mph}$ cruise speed.

Figure 13 compares these air travel block time buildups to the urban ground travel times, indicating a potential 3.0 times improvement in total DtD travel time. The assumed cruise speed is then increased to $200 \mathrm{mph}$ and a 3.6 time improvement in total DtD travel time is observed. If half of the helipad sites that were determined unavailable and thus your ground travel time doubled, a 2.4 and 2.9 times improvement in total DtD trip time could still be achieved. 


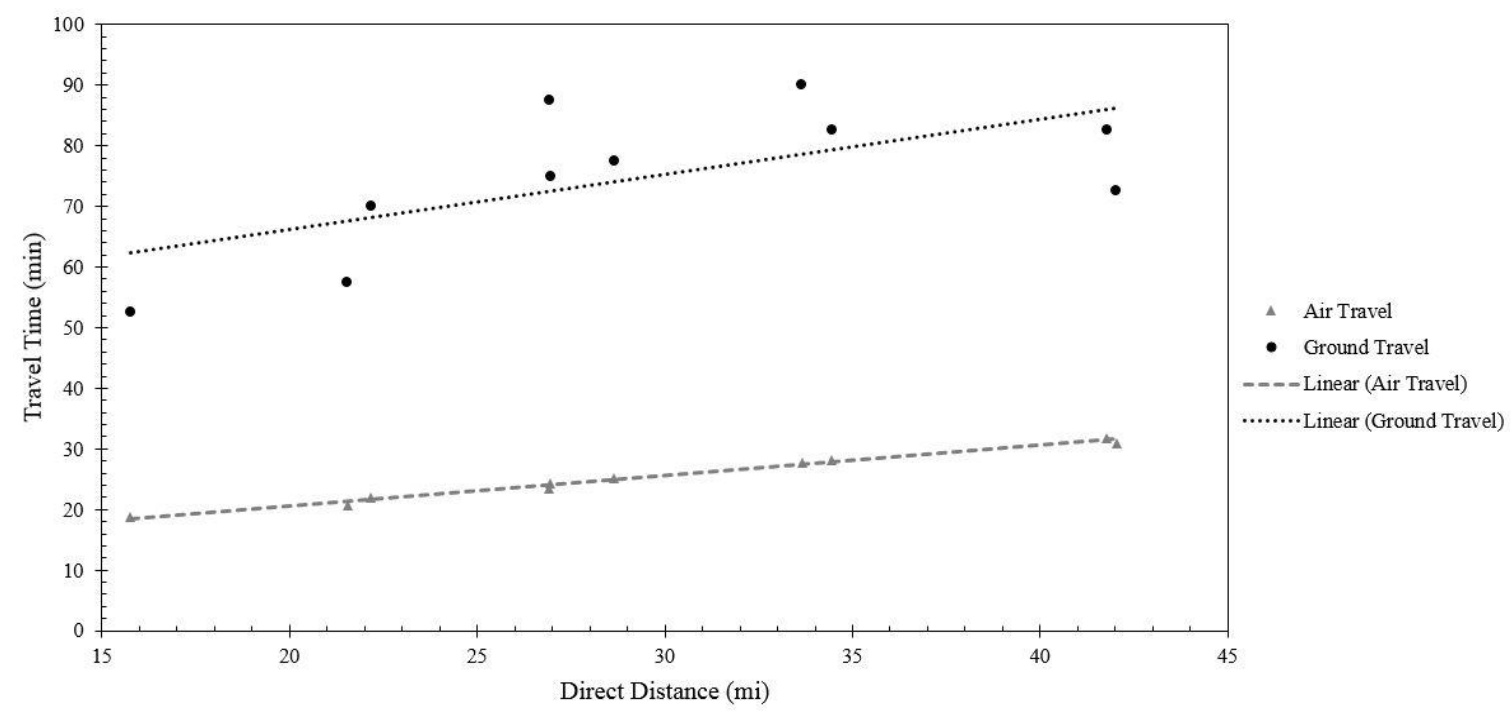

Figure 13. Urban travel time comparison with $120 \mathrm{mph}$ cruise speed.

Block time buildups were also determined for all suburban city pairs with an assumed cruise speed of $120 \mathrm{mph}$. Figure 14 compares these air travel block time buildups to the suburban ground travel times, indicating a potential 2.6 times improvement in total DtD travel time. For these longer suburban travel distances, the increase to a $200 \mathrm{mph}$ cruise speed resulted in a much larger 3.7 times improvement over the average road DtD travel time.

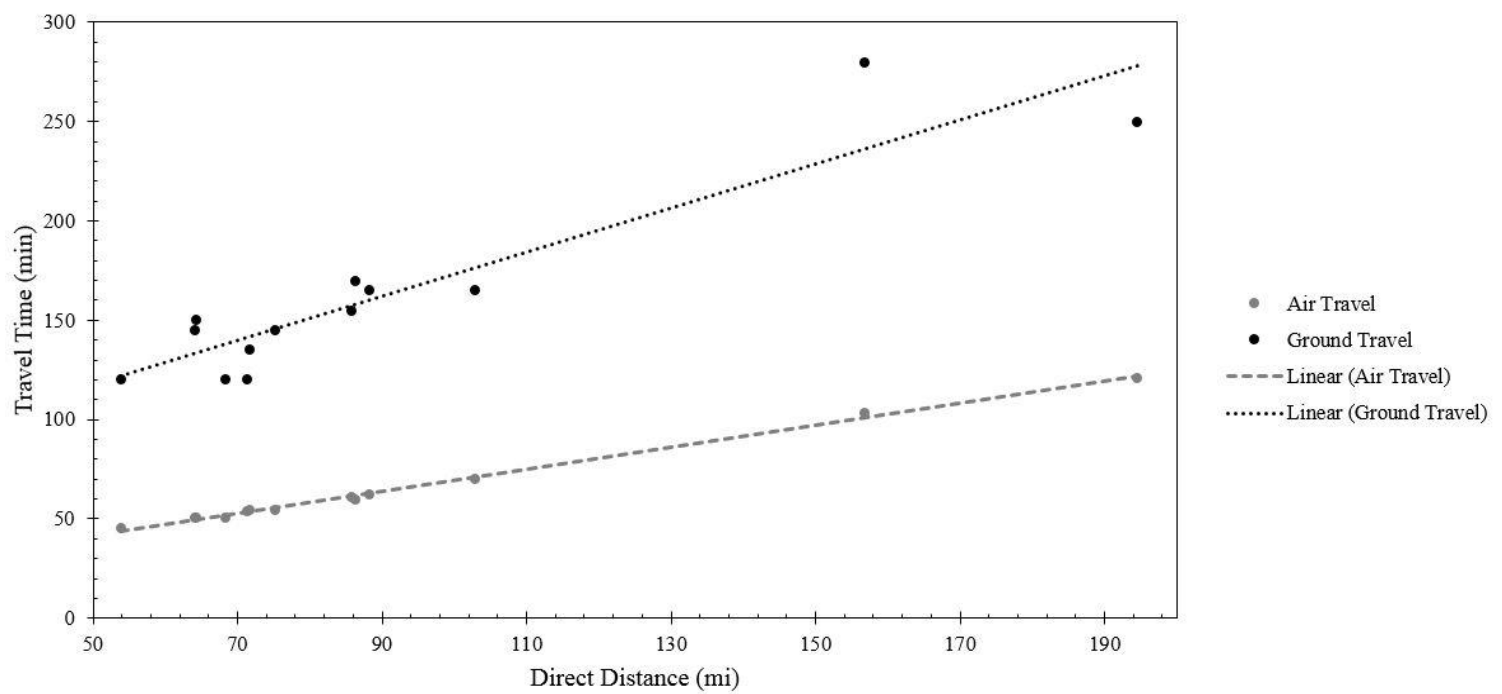

Figure 14. Suburban travel time comparison with 120 mph cruise speed.

\section{Conclusions}

A unique operational concept has been investigated to test the feasibility of achieving highly distributed, ondemand personal transportation in densely populated urban areas through VTOL aircraft air-taxi's. Such a transportation solution provides a path independent approach that can utilize the 3D airspace which is currently underutilized, compared to 1D and 2D ground transportation solutions that are currently oversubscribed and highly congested. The Silicon Valley has been selected as a potential early adopter market to better understand specific geographic issues and promote realistic operational concepts. Specific approaches have been identified to locate a large number of helipads across the region to achieve sufficient distribution, minimize ground travel, and maximize the trip speed. FAA helipad guidance has been used with identification of public and private helipad locations across dense urban and suburban areas. Highway cloverleaf areas are potentially well matched in terms of size to meet helipad needs, location need, acceptability of noise generation, and avoidance of expensive land purchases or 
penalizing neighboring private properties. Practical operational constraints and requirements have been applied, including not being able to fly below 500' altitude over private property. A benefit case has been established with the potential to achieve a $3.5 \mathrm{x}$ improvement in Door-to-Door speeds across urban and suburban trips. Aircraft requirements were derived from the concept of operations, along with constraints. By far the most severe design constraint is the aircraft community noise generated, with radical reductions required compared to existing helicopters to likely meet community expectations for such close proximity operations. Several advanced concepts were developed to meet these requirements which leveraged technologies such as Distributed Electric Propulsion that offer fundamentally new degrees of freedom to design VTOL aircraft that are far better suited to the urban air-taxi mission. A great deal of additional research is required prior to determining the feasibility of this mission concept, however this initial investigation suggests that a compelling benefit case can be established.

\section{Future Work}

Clearly this paper is only providing a broad, cursory set of study results which instead of providing conclusive answers, has identified the many questions that need to be answered across highly diverse analysis involving many discipline experts. Follow-on studies have already been initiated with significantly greater funding to achieve more detailed analysis results. This additional research will include the following research elements.

- Assess the effects of the flown trajectories on existing air traffic using airspace simulation, while investigating the feasibility of planning trajectories to avoid most commercial air traffic. One of the most significant questions that will be answered is a determination of the airspace capacity limits for the Silicon Valley across different assumed levels of near-term and long-term airspace management.

- Implement specific concept approaches designed to meet increasingly detailed CONOPs requirements. These concepts will continue to focus on the ability to achieve ultra-low community noise which is considered the primary feasibility constraint. Additional focus will be on configurations that can assure robust operational safety across non-optimal weather conditions.

- Analyze the effects across mobility metrics of door to door trip speed, carbon emissions, energy cost, and percentage of trips captured. Establishing a clear set of benefits across these metrics is vital for determining the value proposition compared to other potential urban transportation investments.

- Demand modeling using the Transportation Systems Analysis Model (TSAM). ${ }^{17}$ This requires the creation of an urban commuter trip forecast module since TSAM currently only forecasts trips longer than 100 miles. The commuter model also requires identification of feasible access sites and a greater knowledge of the level of Helipad distribution that is achievable in built-up population centers.

- Validation of the shorter range urban demand modeling trip data, with a detailed understanding of commuting traffic flow across specific geographic areas. This will be achieved through the use of aggregated cell phone GPS location data from companies such as AirSage and StreetLight who have developed methods to collect this data and filter it into meaningful transportation data sets. Four population areas have been selected to understand how the initial Silicon Valley area extrapolates, with the addition of Los Angeles, New York/Long Island, and Washington DC.

- Collaboration with MIT through Prof. John Hansman as they perform a similar study focusing on the Los Angeles metropolitan area. Los Angeles, in particular, offers a unique early adopter opportunity due to the abundance of downtown helipads located on buildings resulting from a city ordinance that required all high-rise buildings to have a rooftop helipad between 1974 and 2014 (See Figure 15). Specifically, MIT will focus on understanding strategies for managing dense urban airspace amid Class B conflicts with hub airports such as LAX, as well as other airspace operational concerns.

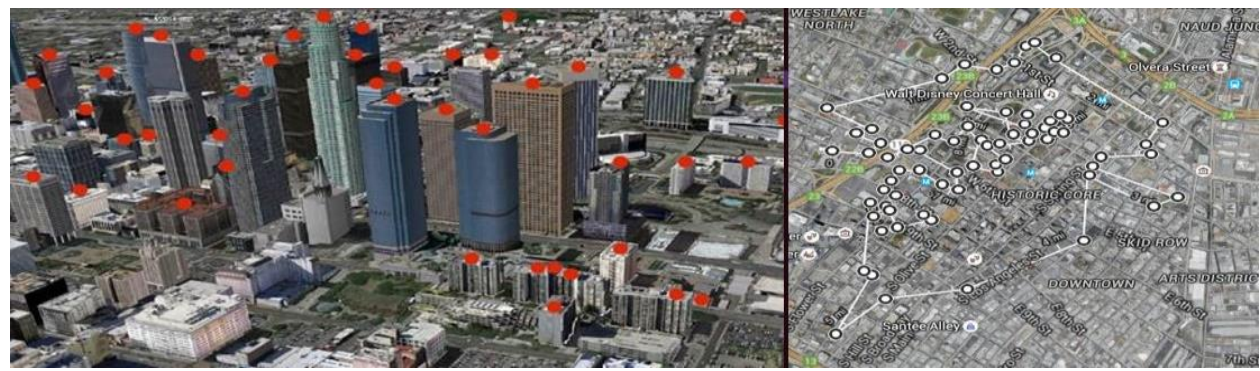

Figure 15. Locations of helipads located on high-rise building rooftops in downtown Los Angeles (courtesy of Joby Aviation). 


\section{Acknowledgments}

The authors are appreciative of the significant feedback provided by the many reviewers as initial versions of this study were presented at the AHS Transformative Vertical Lift Concepts and NASA-FAA On-Demand Mobility workshops over the past year. In particular, the authors are grateful for the leadership provided by AHS Director Mike Hirschberg, Mike Dudley of NASA Ames, and Mike Duffy of Boeing Vertol as they've pursued industry and government interactions to better understand the emerging opportunities for new types of VTOL aircraft, that can enable new civil missions with new business models. Also, the authors wish to thank internal assistance provided by Bill Fredericks, Michael Patterson, Nick Borer, Todd Hodges, and Zak Johns as they've participated in internal NASA review meetings. Most importantly, the authors are thankful for the small companies pioneering the new VTOL aircraft that could make these type of community and user friendly VTOL operations a reality, with huge investments of their time and money to create ultra-quiet VTOL aircraft that can leverage the fantastic autonomy advances. In particular, Joby Aviation has provided leadership across these companies, with a willingness to share their data, knowledge, and vision to promote a future Vertical Lift industry that can benefit all of society in fundamentally new ways.

\section{References}

${ }^{1}$ O’Brien, M., "Google, Facebook in race to build high-altitude aircraft," Mercury News [online periodical], 28 November 2015, URL: http://www.mercurynews.com/business/ci_29177300/google-facebook-race-build-highaltitude-aircraft [cited 16 May 2016].

2 Thompson, C., "The clever way Google X wants to bring clean energy to the masses," Tech Insider [online periodical], 11 August 2015, URL: http://www.techinsider.io/google-x-wants-to-revolutionize-wind-energy-withmakani-power-2015-8 [cited 16 May 2016].

${ }^{3}$ Morgan, D., "Google: Our Drones Will Deliver Packages By 2017," Huffington Post [online periodical], 02 November 2015, URL: $\quad$ http://www.huffingtonpost.com/entry/google-drones-delivery2017_us 56380649e4b00a4d2e0ba5b7 [online periodical], [cited 16 May 2016].

${ }^{4}$ Seppala, T., "Computer vision is key to Amazon Prime Air drone deliveries," Engadget [online periodical], 10 May 2016, URL: http://www.engadget.com/2016/05/10/amazon-prime-air-drone-computer-vision/ [cited 16 May 2016].

${ }^{5}$ Brown, B., "Making the Trip Three Times Faster than Cars, DHL Drones Tested in Mountainous Area," Digital Trends [online periodical], 11 May 2016, URL: http://www.engadget.com/2016/05/10/amazon-prime-air-dronecomputer-vision/ [cited 16 May 2016].

${ }^{6}$ Procter, R., "Alibaba Drone-Delivery Tests Head for Chinese Customers," Readwrite [online periodical], 04 February 2015, URL: http://www.engadget.com/2016/05/10/amazon-prime-air-drone-computer-vision/ [cited 16 May 2016].

7 VTOL For All, "VTOL For All, Tag: electric," VTOL For All [online periodical], 17 January 2016, URL: http://vtolforall.com/tag/electric/ [cited 16 May 2016].

${ }^{8}$ Alonso, J., "System-of-Systems Considerations in the Notional Development of a Metropolitan Aerial Transportation System," Unpublished NASA TM, 2014.

9 Coldwell Banker Mortgage State Licensing, "Home Listing Report 2015," https://www.coldwellbanker.com/hlr/2015 [cited: 5 May 2016]

${ }^{10}$ Rapino, M., Fields, A., "Mega Commuters in the U.S.: Time and Distance in Defining the Long Commute using the American Community Survey," United States Census Bureau, March 2013.

${ }^{11}$ Schafer, A., "Regularities in Travel Demand: An International Perspective," Massachusetts Institute of Technology, December 2000. 
${ }^{12}$ Legal Information Institute, "United States v. Causby et ux.," Cornell University Law School. May 1946. https://www.law.cornell.edu/supremecourt/text/328/256 [cited: 5 May 2016]

${ }^{13}$ Federal Aviation Administration, “Advisory Circular: Heliport Design,” U.S. Department of Transportation, April 2012.

${ }^{14}$ Federal Aviation Administration, "Noise Abatement for Helicopters," Appendix 10 and 11, FAA Advisory Circular 91-66, June 4, 1987.

${ }^{15}$ United States Department of Transportation, "The American Travel Survey," Bureau of Transportation Statistics, 1995.

${ }^{16}$ Moore, M.D., “Affordable Flight Testing of LEAPTech Distributed Electric Propulsion," Oral Presentation, NASA NARI Team Seedling Final Report, 13 January 2015.

${ }^{17}$ Baik, H. and Trani, A., "A Transportation Systems Analysis Model (TSAM) to study the impact of the Small Aircraft Transportation System (SATS),” Virginia Polytechnic Institute and State University, 2005. 